\title{
Educational Content Development to Enhance STEM Learning
}

\author{
https://doi.org/10.3991/ijet.v14i21.11021 \\ Nancy E. Davila-Guzman ${ }^{(凶)}$, Norma Tiempos-Flores, María L. Maya-Treviño, \\ Astrid I. Sanchez-Vazquez, Felipe de Jesus Cerino-Cordova \\ Universidad Autónoma de Nuevo León, Nuevo León, México \\ nancy. davilagz@uanl . edu. mx
}

\begin{abstract}
In this study, multidisciplinary teams were formed to develop educational content as digital videos to help in the learning process in Science, Technology, Engineering and Mathematics (STEM) education. The usefulness of the web-learning tool was evaluated by surveys and tests taken by chemical engineering freshman students. The results showed that these students' scores were higher than the scores obtained by students of previous courses where the web-learning tool was not employed. On the other hand, the audience analysis indicated that the average age is $18-24(91.2 \%)$ and the gender distribution was $54.9 \%$ male and $46.6 \%$ female from different countries (Mexico, Colombia, Spain, U.S., among others).
\end{abstract}

Keywords-Autonomous learning; e-learning; learning technology; engineering

\section{Introduction}

The percentage of enrolment to postsecondary education has increased over the last few decades [1], [2]. In the UK, it is expected an increase of $31 \%$ in full-time England-domiciled undergraduate entrants by 2030 [3]. Thus, the number of students per classroom is constantly growing, making the teaching process more difficult [4]. On the other hand, the worldwide internet access has increased more than 600 percent since 2000 [5], [6], and the internet access of the 16-24 age group population has increased as well. For instance, in the UK it has increased from $81 \%$ to $95 \%$ since 2011[7]. As a result, web-based learning techniques have emerged as learning support tools by taking advantage of technology in the teaching-learning process [8]-[11]. One of these learning tools is digital video which is an instructional media that has become popular because the information is presented in an attractive manner that makes students learn more enthusiastically [12], [13]. Moreover, Merkt et al., [14] demonstrated that learning with videos is comparable or even superior to learning with illustrated textbooks because the learners can match the pace of information to their own cognitive level. Jackman [15] considers digital media, such as digital videos, as an unique educational e-resource. Furthermore, digital videos have been applied to enhance Science, Technology, Engineering and Mathematics (STEM) education. 
For instance, video-based learning has become an effective method that enhances the learning performance of medical students [16]-[20]. Also, Abulencia et al., [21] used video media to enhance conceptual learning in a thermodynamics course. They concluded that watching and making videos enhance the affective domain and conceptual learning of the students. Barns et al., [22] evaluated the impact of worked-example videos (WEV) in maths-heavy undergraduate engineering units at the Queensland University of Technology over three semesters. They found that WEV improved the understanding of technical content by the media controls that allow to pause and rewind the video, which lead to personalised learning.

The aim of this work is to present a methodology to make a web-based learning tool that requires low investment and the integration of a multidisciplinary team to enhance the students' outcomes in STEM education and their learning process.

\section{Materials and Methods}

In its current iteration, the web-based learning tool is a YouTube channel named CienciasIQ UANL that has been created for uploading several videos that explain chemistry concepts. To make these videos, a four-stage methodology was employed:

- Equipment and staff: For making the educational videos, it was necessary to acquire one kit of lights, 3 softboxes and one audio mixer with an approximate total cost of $€ 500$. The staff that recorded and produced the videos was composed of two art students (bachelor of language and audio-visual production) that participated in this program as part of their social service. Chemical engineering bachelor students volunteered to participate as presenters.

- Selection of topics: Chemistry professors were asked about the concepts that their students usually struggle to understand. Then, the topics were selected for the first phase of this program.

- Scripts: The topics selected were assigned to the chemical engineering bachelor volunteers (CEBV). The CEBV made the scripts in a text processor and a schematic script that included images and the sequence that must be followed for better understanding of the topic. The chemistry professors checked the scripts made by the CEBV and some corrections were made when needed.

- Showtime: The final scripts were delivered to the staff. The equipment was assembled by the art students in a conference room provided by the institution. The presenters read the scripts in sections until the last slide. Then, the art students edited the videos and added the logo and copyright free music. After, the program coordinator and the professors checked the videos to ensure there are no errors. Finally, the program coordinator uploaded the videos to the channel (www.youtube.com/chan nel/UCtjyH5zxyqC1scNBkaAgaFg) and promoted the channel on social networks (Figure 1). 


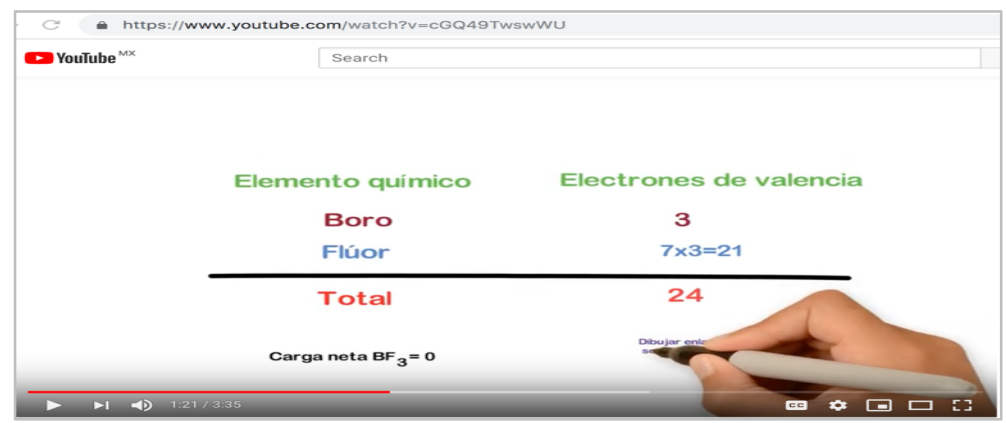

Fig. 1. Screenshot of the CienciasIQ UANL channel. More than 129,000 visits.

\section{Results and Discussion}

In order to evaluate the effect of the web-based learning tool on chemical engineering students, the chemistry professors asked their students to watch the videos of three specific topics: limiting reagent, cations and anion nomenclature, and double titration. For the first two topics, the professors used the video only as an enforcement tool, to increase the understanding of the students about the topics. Next, the comprehension of the students was evaluated by a test and the scores were compared with those obtained by the students enrolled in the fall semesters of 2014 and 2015. In the case of the double titration topic, the professor first asked the students to watch the video and then, the students were asked to solve double titration exercises using only the knowledge acquired through the double titration video. Again, the scores were compared to those obtained by the students enrolled in the fall semesters 2014 and 2015. According to the results shown in Figure 2, the student scores were higher than the scores obtained by the students of the previous courses where the web-learning tool was not employed. For instance, in the comprehension of the nomenclature topic, the percentage of students that obtained a very good score (91-100) was increased by 2.11 fold and 6.5 fold compared to the scores obtained in fall semesters 2014 and 2015, respectively.

Furthermore, the percentage of students that obtained unsatisfactory scores was reduced from $60 \%$ in the fall semester 2014 to $23 \%$ in the fall semester 2016. Similar results were obtained in the evaluation of the other topics.

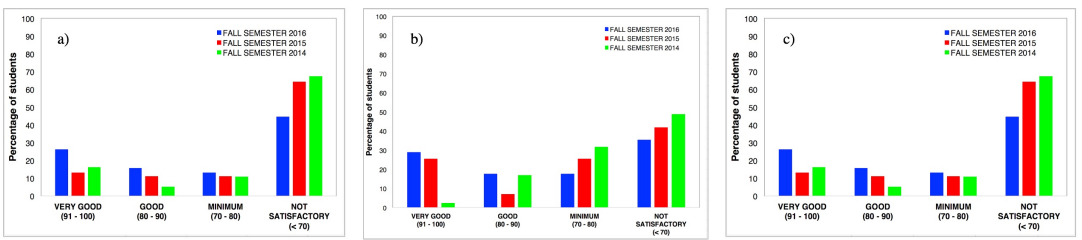

Fig. 2. Comparison of students' scores using the web-based learning tool (fall semester 2016) and without it (fall semesters $2014 \&$ 2015). Topics evaluated: a) anion and cation nomenclature, b) limiting reagent, and c) double titration 
Finally, the students were asked to answer a survey about the usefulness of the web-based learning tool where the Likert scale, the most common rating scale used in education contexts, was employed to measure the satisfaction of the students. The survey was anonymous and it comprises five questions:

- How much do you think you learned about double titration by reading the textbook?

- How much do you think you learned about double titration by listening to your professor?

- How much do you think you learned about double titration by using the YouTube channel "CienciasIQ UANL"?

- The subject double titration was easier to understand when exposed by students in the YouTube Channel "CienciasIQ UANL" than by the teacher.

- The videos of the YouTube channel "CienciasIQ UANL" are useful tools as a supporting material for increasing my meaningful learning.

This survey was applied to evaluate the comprehension of different subjects, such as: anion and cation nomenclature, limiting reagent and double titration. The results show that the students had a better understanding when the topic was explained to them by students rather than by the professor (Figure 3). It is well-known that peerteaching technique, i.e. students teaching students, is underlined by the social constructivism theory, where a student teacher and student learner have a short cognitive level gap, making the learning process more suitable. When the students were asked if the web-based learning tool was a useful tool for their meaningful learning, $42 \%$ of the students chose agree or totally agree while $11 \%$ chose disagree or strongly disagree, the rest remained neutral.

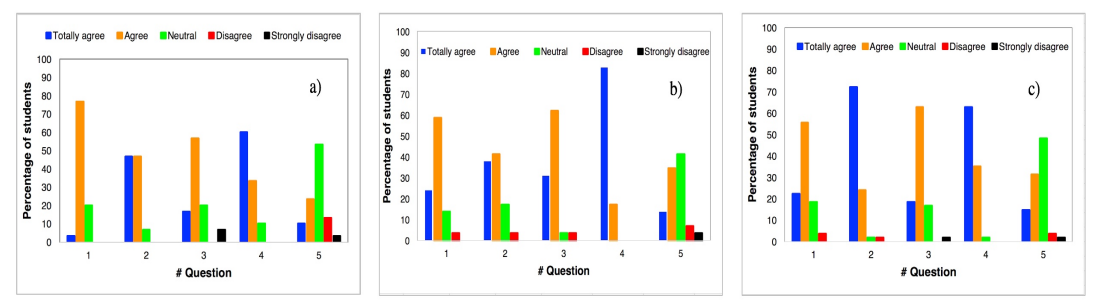

Fig. 3. Results of the survey about the usefulness of the web-based learning tool. Topics evaluated: a) anion and cation nomenclature, b) limiting reagent, and c) double titration

On the other hand, it was analyzed the audience of the educational videos by means of YouTube Analytics data. The results showed that the videos were view by people from different countries such as Mexico, Colombia, Argentina, Spain and United States (Figure 4) and a total of 129,215 views were registered since 2016 until now. Also, the demographics analysis of the audience indicate that the average age is 18-24 $(91.2 \%)$ and the gender distribution was $54.9 \%$ male and $46.6 \%$ female (Figure 5). 


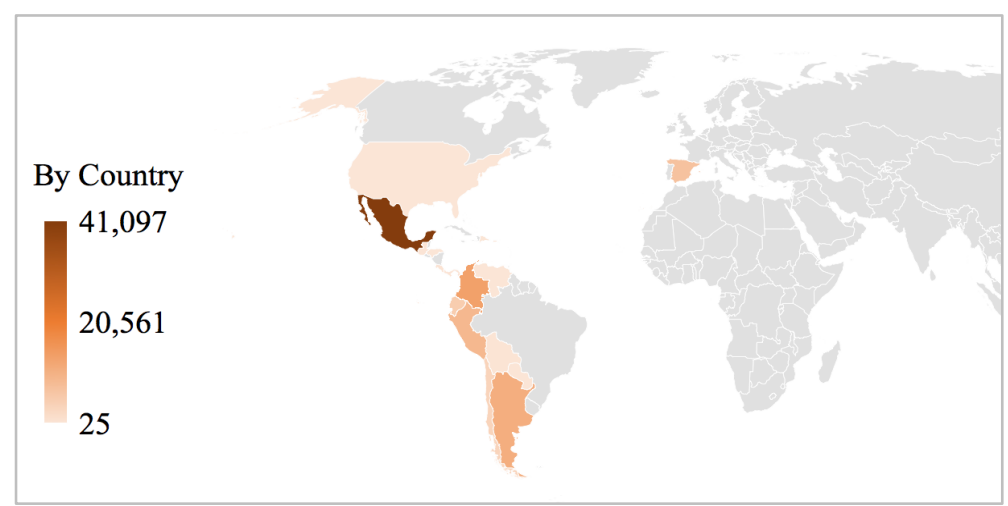

Fig. 4. Geographic analysis of the audience of the educational videos.

Finally, the web-based learning tool was promoted on social networks. The promotion received great response from the chemical engineering students who became subscribers to the channel. These educational videos received comments from professors and students from other institutions and other countries who also promoted them on their social networks. Furthermore, undergraduate and graduate students showed interest by participating in the development of scripts and as presenters of other topics related to chemical engineering. The next phase of this program is to follow this methodology with new art school students and chemical engineering professors to increase the number of videos on other topics such as: programming for chemical engineers, mass and energy balance, transport phenomena, separation processes, chemical reactors and so on.

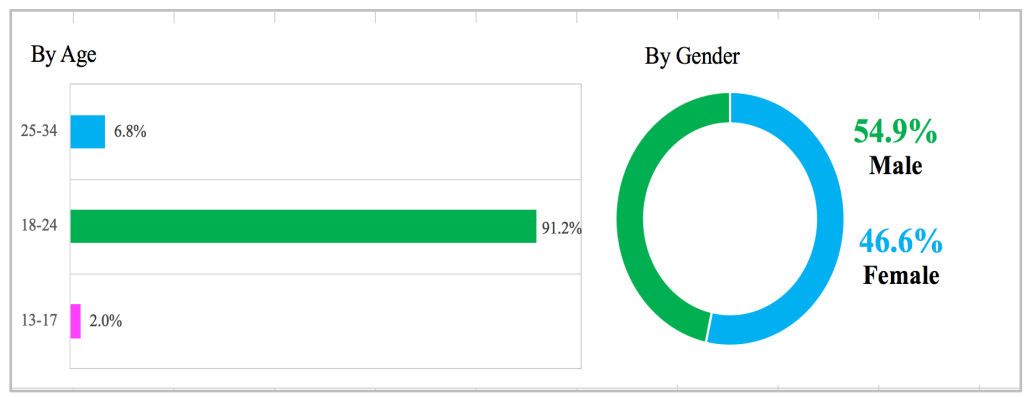

Fig. 5. Demographic analysis of the audience of the educational videos.

\section{Conclusion}

The comprehension of the engineering students on chemistry topics is increase by the use of the educational videos produced under the methodology proposed. Furthermore, the unsatisfactory scores in the chemistry test taken by the engineering students was reduced by using the educational videos. Also, the methodology pro- 
posed for the production of the educational video allowed to engage audience from different countries. It can be concluded that the use of the web-based learning tool enhanced the students outcomes.

\section{Acknowledgement}

The authors are grateful to Eduardo Soto-Regalado (Dean of the School of Chemical Sciences at UANL) for supporting this project and to Jesus Botello Gonzalez. They would also like to thank art students Oseas M. Tamez Cardenas and Valerie D. Aurrecoechea Castillo for producing the videos; and thank the cast members Lariza F. Rodriguez Cepeda, Valdemar E. de la Paz Cavazos, Iliana Salinas Cantu, Enrique J. Salinas Villarreal, Mariana Alejos Garza, Oscar F. Najera Vazquez, and Jose A. Acosta Valdez, for their participation.

\section{$6 \quad$ References}

[1] T. Ross et al., "Higher Education: Gaps in Access and Persistence Study," National Center for Education Statistics, Aug. 2012.

[2] R. A. da Silva TL, "Contributors to academic failure in postsecondary education: A review and a Canadian context.," Int J Non-Commun Dis , vol. 1, pp. 9-17, 2016. https://doi.org/ $\underline{10.4103 / 2468-8827.184854}$

[3] B. Bekhradnia and D. Beech, "Demand for Higher Education to 2030," 2018.

[4] R. Monahan, "City schools have thousands of overcrowded classes, students sitting on floors or standing in doorways: union officials - NY Daily News," New York Dialy News, 2013. [Online]. Available: http://www.nydailynews.com/new-york/education/city-schoolsthousands-overcrowded-classes-union-officials-article-1.1469125. [Accessed: 06-Jun2018].

[5] World bank, "Individuals using the Internet (\% of population) | Data," World Development Indicators, The World Bank, 2017. [Online]. Available: https://data.worldbank.org/indica tor/IT.NET.USER.ZS. [Accessed: 06-Jun-2018].

[6] S. Kemp, "Digital in 2018: World's internet users pass the 4 billion mark," We Are Soc., no. January, p. 260, 2018.

[7] Statista, "Internet access at home, by age group 2011-2017 | UK Statistics," 2017. [Online]. Available: https://www.statista.com/statistics/272970/internet-access-at-home-in-theunited-kingdom-uk-by-age-group/. [Accessed: 07-Jun-2018].

[8] P. Chatwattana and P. Nilsook, "A Web - based Learning System using Project - based Learning and Imagineering," Int. J. Emerg. Technol. Learn., vol. 12, no. 05, pp. 4-22, 2017. https://doi.org/10.3991/ijet.v12i05.6344

[9] D. Bridges, "Back to the Future: The higher education curriculum in the 21st century," Cambridge J. Educ., vol. 30, no. 1, pp. 37-55, 2000.

[10] A. Gouseti, "An overview of web-based school collaboration: A history of success or failure?," Cambridge J. Educ., vol. 43, no. 3, pp. 377-390, 2013. https://doi.org/10.1080/0305 $\underline{764 x .2013 .792785}$

[11] K. Laeeq and Z. A. Memon, "An Integrated Model to Enhance Virtual Learning Environments with Current Social Networking Perspective," pp. 252-268. https://doi.org/10.3991/ ijet.v13i09.8000 
[12] P.-S. Chiu, H.-C. Chen, Y.-M. Huang, C.-J. Liu, M.-C. Liu, and M.-H. Shen, “A video annotation learning approach to improve the effects of video learning," Innov. Educ. Teach. Int., vol. 55, no. 4, pp. 459-469, Jul. 2018. https://doi.org/10.1080/14703297.2016.121365 $\underline{3}$

[13] P. L. Mosley, "Lecture Video: Characteristics and Utilizations as an Online Learning Resource," 2017, pp. 91-100.

[14] M. Merkt, S. Weigand, A. Heier, and S. Schwan, "Learning with videos vs. learning with print: The role of interactive features," Learn. Instr., vol. 21, no. 6, pp. 687-704, Dec. 2011. https://doi.org/10.1016/j.learninstruc.2011.03.004

[15] W. M. Jackman, "YouTube Usage in the University Classroom: An Argument for its Pedagogical Benefits,” Int. J. Emerg. Technol. Learn., vol. 14, no. 09, p. 157, 2019. https://doi. org/10.3991/ijet.v14i09.10475

[16] A. Ahmet, K. Gamze, M. Rustem, and K. A. Sezen, "Is Video-Based Education an Effective Method in Surgical Education? A Systematic Review," J. Surg. Educ., pp. 1-9, 2018. https://doi.org/10.1016/j.jsurg.2018.01.014

[17] A. Clifton and C. Mann, "Can YouTube enhance student nurse learning?," Nurse Educ. Today, vol. 31, no. 4, pp. 311-313, 2011. https://doi.org/10.1016/j.nedt.2010.10.004

[18] R. Lehmann, A. Seitz, H. M. Bosse, T. Lutz, and S. Huwendiek, "Student perceptions of a video-based blended learning approach for improving pediatric physical examination skills," Ann. Anat., vol. 208, pp. 179-182, 2016. https://doi.org/10.1016/j.aanat.2016.05. $\underline{009}$

[19] O. W. May, M. G. Wedgeworth, and A. B. Bigham, "Technology in Nursing Education: YouTube as a Teaching Strategy,” J. Pediatr. Nurs., vol. 28, no. 4, pp. 408-410, 2013. https://doi.org/10.1016/j.pedn.2013.04.004

[20] P. Mota, N. Carvalho, E. Carvalho-Dias, M. João Costa, J. Correia-Pinto, and E. Lima, "Video-Based Surgical Learning: Improving Trainee Education and Preparation for Surgery," J. Surg. Educ., vol. 75, no. 3, pp. 828-835, 2017. https://doi.org/10.1016/j.jsurg.20 $\underline{17.09 .027}$

[21] J. P. Abulencia, M. A. Vigeant, and D. L. Silverstein, "Using video media to enhance conceptual learning in an undergraduate thermodynamics course," Proc. 2012 Am. Soc. Eng. Educ. Annu. Conf. Expo., p. n/a, 2012.

[22] S. Barns, E. Pickering, and L. Dawes, "Worked Example Videos as a Valuable Blended Learning Resource in Undergraduate Engineering Units," in 28th Annual Conference of the Australasian Association for Engineering Education (AAEE 2017), 2017, pp. 1-8.

\section{Authors}

Nancy E. Davila Guzman received her PhD in Sustainable Processes in 2013 from Universidad Autónoma de Nuevo Leon (UANL), where she is currently full professor at the School of Chemical Sciences. She is the coordinator of the Sustainable Processes Graduate Program and the Leader of the research group of Chemical Engineering at UANL. Her research interests are mass transfer studies, mathematical modeling, adsorption mechanism, adsorption in gas-solid and liquid-solid phases, programming, and STEM education. E-mail: nancy.davilagz@uanl.edu.mx

Norma Tiempos Flores received her M.Sc. in Organic Chemistry in 2005 from Universidad Autónoma del Estado de Morelos. She is currently an Associate Profes- 
sor and coordinator of Basic Sciences at the School of Chemical Sciences, UANL. Email: norma.tiemposflr@uanl.edu.mx.

María de Lourdes Maya Treviño received her B. Sc. in Industrial Chemistry in 2005, M. Sc. in Materials Chemistry in 2008 and, Ph.D. in Enviromental Analytical Chemistry in 2013 from School of Chemical Sciences at UANL. Since 2014, she is Full-time Professor at School of Chemical Sciences, UANL. The courses imparted are: Chemistry of the Environmental Systems at Postgraduate level, Inorganic Chemistry, General Chemistry, Polymers, Materials Properties, Laboratory of Organic Chemistry, Laboratory of Equilibrium Chemistry, Laboratory of Physicochemistry I, at B. Sc. Level. Her research interests are synthesis of semiconductors and the evaluation of their photocatalytic and antibacterial properties. E-mail: maria.mayatv@uanl.edu.mx.

Astrid Iriana Sánchez Vázquez received his $\mathrm{PhD}$ degree in Materials Chemistry from Universidad Autonoma de Nuevo Leon (UANL). She is full professor at the Shcool of Chemical Sciences, UANL, where she teaches Analytic Chemistry and Chemical Equilibrium courses. Her research interests are recycle of industrial waste to produce new materials as glass and ceramics, and chemistry education. E-mail: astrid.sanchezvz@uanl.edu.mx, asirian@yahoo.com.mx.

Felipe de Jesús Cerino Córdova obtained his Ph.D. in Process Engineering in 2003 from Institut Polytechnique de Grenoble, France, MSc in Process Engineering in 1995 from Instituto Tecnólogico de Celaya (México) and B. Sc in Chemical Engineering from Universidad Juarez Autónoma de Tabasco. He was chairman of Chemical Engineering and Environmental Engineering Department from School of Chemical Sciences of Universidad Autónoma de Nuevo León (UANL). He is currently Professor at the Mechanical and Electrical Engineering School at UANL. His research interests are adsorption process, bioprocess and wastewater treatment. E-mail: felipe.cerinocr@uanl.edu.mx.

Article submitted 2019-06-12. Resubmitted 2019-07-18. Final acceptance 2019-07-18. Final version published as submitted by the authors. 